\title{
Income Sustainability through Educational Attainment
}

\author{
Ronald H. Carlson ${ }^{1}$, Christopher S. McChesney ${ }^{1}$ \\ ${ }^{1}$ Indian River State College 3209 Virginia Ave., Fort Pierce, FL 34953, USA \\ Correspondence: Christopher S. McChesney, Indian River State College 3209 Virginia Ave., Fort Pierce, FL 34953, \\ USA
}

Received: September 5, 2014

Accepted: September 22, 2014 Online Published: December 24, 2014

doi:10.11114/jets.v3i1.508

URL: http://dx.doi.org/10.11114/jets.v3i1.508

\begin{abstract}
The authors examined the sustainability of income, as it relates to educational attainment, from the two recent decades, which includes three significant economic downturns. The data was analyzed to determine trends in the wealth gap, parsed by educational attainment and gender. Utilizing the data from 1991 through 2010, predictions in changes in the wealth gap and standard of living, as it relates to educational attainment, was made through the year 2030. The research supported a positive correlation between education levels and salaries, independent of economic conditions in the United States. Thus, the higher the education level achieved, the higher the earnings, and the lower the volatility during periods of economic downturn. Furthermore, the results indicated that a Bachelor Degree only ensured equilibrium with inflationary increases over the two decades. The real earnings, adjusted for inflation, of all educational levels below the Bachelor's Degree declined over the twenty year period. Thus, the wealth gap is increasing as real earnings have stayed constant or declined for nearly $90 \%$ of all workers in the United States. In addition, while there is still a significant gap between female and male earnings, females fared significantly better than their male counterparts, in terms of changes in annual earning's. The predictions have shown that the wealth gap will continue to widen over the next two decades, based on current trends. In general terms, the authors conclude that the buying power and standard of living in the United States is declining for all education levels below a Bachelor's Degree.
\end{abstract}

Keywords: income, education, standard of living, inflation, sustainability, real wage growth, gender equality

\section{Introduction}

An advanced education is one of the largest financial expenditures that most people will make in their lives. It is, therefore, important that a college education actually translates to an sustainable increase in income beyond that which would have been earned without the degree. While there have been a number of cost-value studies during periods of economic growth, the extent to which higher education benefits degree holders during periods of economic downturn is unknown. The researchers set out to determine the degree of evidence for education preserving or increasing income and employability values, and to what extent, if at all.

A quantitative comparative analysis was conducted for the years 1991-2010 on income, as it relates to educational attainment. The data was parsed by gender to further study the implications of educational attainment on income throughout the two decades. There were three interrelated purposes behind the research. The first was to examine the perceived value of higher education that currently guides millions of people in their decision to pursue a higher education in the United States. The second purpose of the research was to examine whether the gap in wealth between the lower and higher education levels was increasing. The third purpose was to measure the impact of the salary changes for female workers. This research adds to the body of scholarly knowledge by providing an analysis of the impact of educational attainment on the sustainability of income and real income growth, regardless of economic conditions.

\section{Material Studied}

Peer reviewed literature, scholarly research and mainstream media articles were analyzed and gathered into useable results. Data was gathered from: U.S. Department of Commerce, Census Bureau, Current Population Reports, Series P-60, Money Income of Households, Families, and Persons in the United States and Income, Poverty, and Valuation of Noncash Benefits, 1990 through 1994; Series P-60, Money Income in the United States, 1995 through 2002; and Detailed Income Tabulations from the CPS, 2003 through 2010. 


\section{The Research Study Hypotheses}

- There is a positive correlation between education levels and salaries independent of the economic conditions in the United States.

-Salary levels for female workers are increasing at a more rapid rate than their male counterparts.

-The wealth gap in the United States between education levels is increasing independent of the economic conditions in the United States.

-The wealth gap will continue to widen over the next two decades, based on current trends.

In the United States, the wealth gap between the top few percent and the median income earners is sizeable (Hendricks, 2007). The income GINI coefficients and other research indicate that the earnings in the United States are becoming increasingly inequitable. In a study including all of the developed nations across the globe, only Portugal and Mexico have a wider gap between the wealthy and the poor (Moriguchi, 2008). Thus, a study in the wealth gap trends, as related to educational attainment, was a necessity.

\section{Methods}

A quantitative comparative design was the basis for the study conducted. Peer reviewed literature, scholarly research and mainstream media articles were analyzed and gathered into useable results.

\subsection{Economic Downturn}

A major economic downturn is referred to as a recession. The technical indicator of a recession is two consecutive quarters of negative economic growth, as measured by a country's gross domestic product (GDP). While this is the "official" recession indicator utilized in the United States, it does not reflect the full complexity of an economic downturn. In contrast, the National Bureau of Economic Research offers a much broader definition of a recession, which takes into account the full scope of an economic downturn.

\subsection{Recession}

The official National Bureau of Economic Research NBER definition of recession (which is used to date U.S. recessions) is: A recession is a significant decline in economic activity spread across the economy, lasting more than a few months, normally visible in real GDP, real income, employment, industrial production, and wholesale-retail sales. A recession begins just after the economy reaches a peak of activity and ends as the economy reaches its trough. Between trough and peak, the economy is in an expansion (Harvey, Morgenson, 2002).

The NBER definition of a recession is utilized in this study. As a result, since 1941, the United States has experienced an economic recession every seven to ten years.

\subsection{The High Cost of a College Education}

In the United States, a college education is a highly valued commodity that requires a substantial financial outlay. In 2011 , undergraduate college tuition, including room and board, was estimated at an average $\$ 13,600$ for public colleges and $\$ 36,000$ for private colleges. Many colleges have higher fees, some peaking at over $\$ 100,000$ to attain a 4 year Bachelor's Degree. Prices rose 42\% at public colleges from 2000-2011, and 31\% at private colleges (National Center for Education Statistics, 2012). With such a high cost for education, it is imperative to know the correlation between the cost of education, salary, and lifetime wealth attainment.

According to data obtained from Bureau of Labor, BLS (2012), the median weekly earnings per year, for those wage and salary workers employed full time (age 25 and over) is significantly higher for those with a Bachelor's Degree than those with an Associate's Degree, some college, or high school diploma. Workers with a Bachelor's Degree earn nearly double the income of a high school graduate, which adds up to a significant amount of income over the span of a career. This study also illustrates that the wealth gap between those two groups has widened. In the year 2000, those with a Bachelor’s Degree earned \$322 more per week than those with a high school diploma; in 2012, the Bachelor's Degree group earned almost $\$ 400$ more per week, which supports the theory of an ever widening wealth gap.

\section{Results}

As of recent, the value of a college education has come under scrutiny. Since 1962, the percentage of the population with "some college" or higher has steadily increased, with the exception of 1991-1994 when college enrollment temporarily spiked to a 5.9\% increase (Figure 1). This continual increase in the number of college graduates has brought into question the value of the college education, due to a change in the supply/demand of educated workers. 


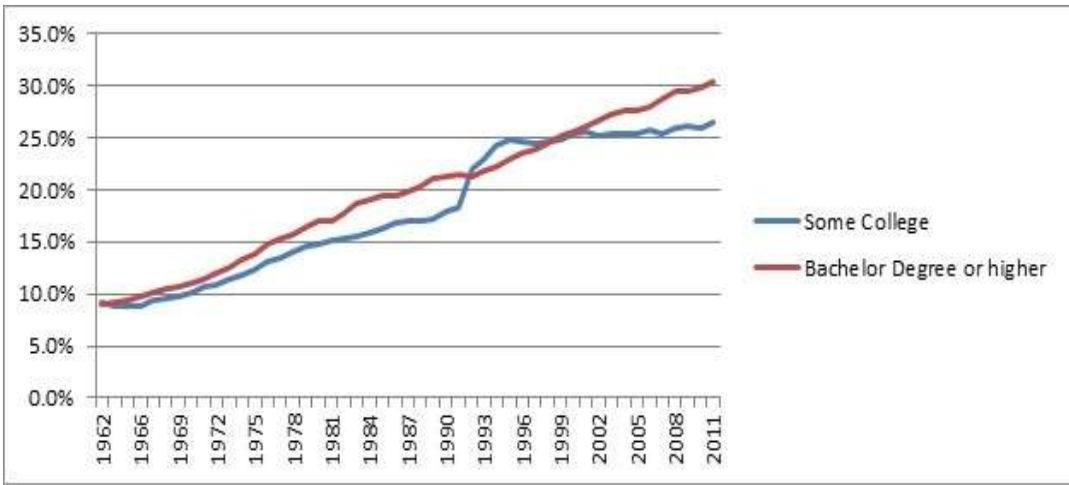

Figure 1. Degree Attainment (people 25 years and older)

According to the 2010 American Community Survey, approximately 204 million people in the US were age 25 and over; of those 204 million people $28.4 \%$ received a high school diploma or GED; $21 \%$ completed some college; $17.6 \%$ received a bachelor's degree; $10.2 \%$ received a graduate or professional degree; $8.3 \%$ completed some high school; 7.3\% received an AA degree; and 5.3\% attained less than a 9th grade education.

Table 1. Salary Change

\begin{tabular}{ccc}
\hline Salary Change - In Current Dollars & \multicolumn{2}{c}{ Arithmetic Sum } \\
\hline Educational Level & Male & Female \\
\hline < 9th grade & $33.7 \%$ & $43.5 \%$ \\
Some High School & $33.2 \%$ & $38.0 \%$ \\
High School & $41.2 \%$ & $47.0 \%$ \\
Some College & $39.0 \%$ & $42.1 \%$ \\
Associates Degree & $40.7 \%$ & $42.0 \%$ \\
Bachelor's Degree & $45.6 \%$ & $50.0 \%$ \\
Master's Degree & $50.3 \%$ & $54.1 \%$ \\
Professional Degree & $48.6 \%$ & $56.3 \%$ \\
Doctorate Degree & $61.4 \%$ & $61.9 \%$
\end{tabular}

It is important to address the common misconception that higher salaries, over time, equate to a higher standard of living and more buying power. As illustrated in Table 1, the current dollar arithmetic sum of annual percentage salary increases range from $33.2 \%$ to $61.9 \%$, which illustrates that everyone is making substantially more in 2010 than they were in 1991, regardless of educational attainment. In addition, the data shows a correlation between the salaries and the educational attainment level. The higher the educational achievement, the higher the associated average salary. The current dollar amounts, however, do not take into consideration the effects of inflation on the salaries, which is an important component when determining buying power and standard of living comparisons.

Inflation reduces the buying power of each dollar received. As a result, it reduces the standard of living unless the annual salary increase is large enough to cover the annual inflationary increases in the price of goods and services, as measured by the inflation index. In the case of annual inflation of 3\% and an annual salary increase of $4 \%$, the individual would have an increase of $1 \%$ in buying power, since the salary increase of $4 \%$ not only covers the price increases of $3 \%$, but is $1 \%$ higher. In contrast, if the percentage annual salary increase is $2 \%$ and inflation is $3 \%$, the individual loses $1 \%$ in buying power, which results in a decrease in standard of living, even though the salary is higher in number than the previous year. It is imperative, therefore, to include the effects of inflation on the salaries, which is 
accomplished by using real dollars, as this adjusts the salary for the effects of inflation. Real dollars were used throughout this study to cover the effects of inflation.

Table 2. Percentage Salary Changes 1991 to 2010 Constant U.S. Dollars

\begin{tabular}{llc}
\hline Salary 1991 - 2010 Real Dollars & \multicolumn{2}{c}{ Arithmetic Sum } \\
\hline Education Level & Male & Female \\
< 9th grad & $-13.6 \%$ & $-4.1 \%$ \\
Some High School & $-14.3 \%$ & $-9.4 \%$ \\
High School & $-6.3 \%$ & $-0.7 \%$ \\
Some College & $-8.4 \%$ & $-5.3 \%$ \\
Associates Degree & $-6.8 \%$ & $-5.5 \%$ \\
Bachelor's Degree & $-2.2 \%$ & $2.2 \%$ \\
Master's Degree & $2.4 \%$ & $6.3 \%$ \\
Professional Degree & $1.6 \%$ & $8.7 \%$ \\
Doctorate Degree & $13.2 \%$ & $14.0 \%$ \\
\hline
\end{tabular}

As illustrated in Table 2, using the annual salary change in real 2010 dollars, it is evident that a male or female with a Master's Degree, Professional Degree, or a Doctorate Degree have increased their buying power, and hence their standard of living, over the twenty year period, 1991 through 2010. In contrast, Bachelor's Degree holders, males with a decrease of $-2.2 \%$ and females with an increase of $2.2 \%$ in buying power, have merely kept pace with inflation. All education levels below a Bachelor's Degree, male and female, confirm a decrease in buying power over the 20 year period.

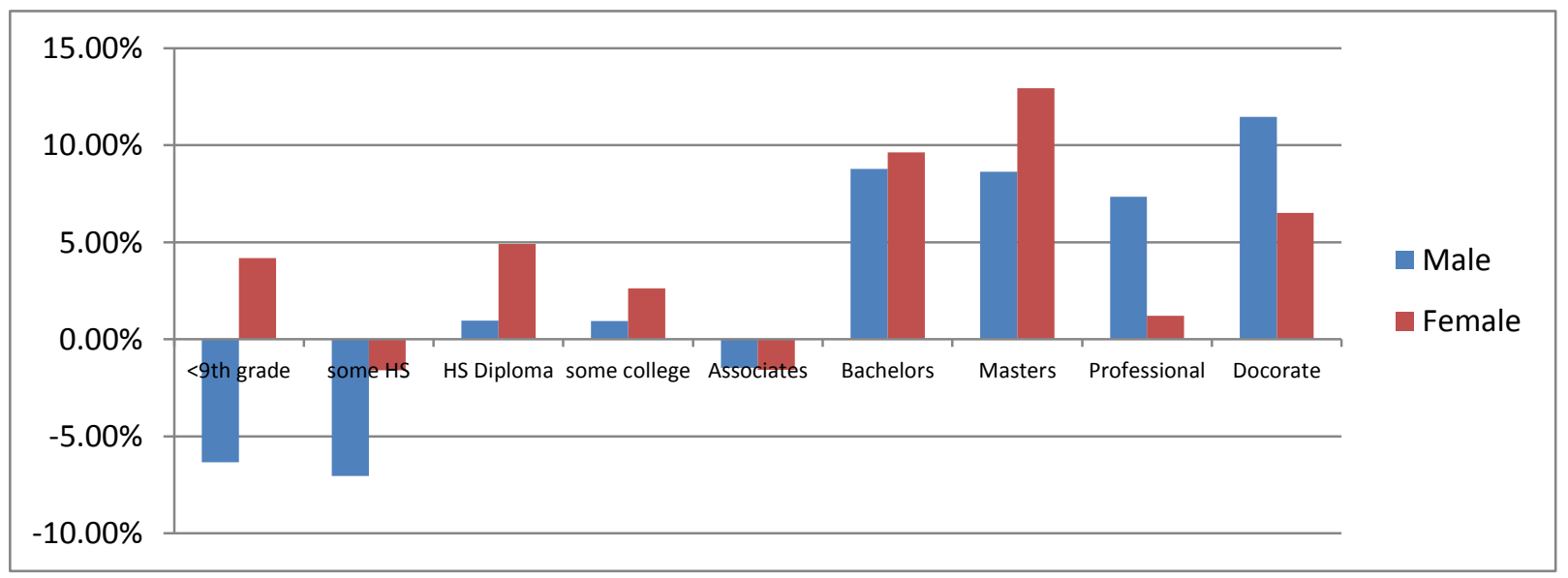

Figure 2. 1991-2000 Real Salary Changes

Figure 2 illustrates the changes in salary adjusted for inflation from 1991 through 2000. Due to the economic fluctuations during that decade, the pattern is erratic. Despite fluctuations, the data shows significant increases for both males and females in all educational attainment levels above the Associate's Degree level, with the exclusion of the Professional Degree for females. Also noteworthy, females fared consistently better than their male counterparts in all educational attainment levels during the decade, barring only the Associate's, Professional, and Doctorate Degree.

The next decade of study (Figure 3) included the changes in salary adjusted for inflation from 2001 through 2010. While this decade also experienced economic fluctuations, including a major recession, the pattern is less erratic than the previous decade. This decade was beneficial to the study because it provided the necessary data to determine salary patterns during times of economic downturn. The data shows increases for both males and females in the Doctorate attainment level and an increase in the Professional level for females. All other educational attainment levels showed a decrease in salary, including males at the Professional level. As a result, females fared significant better than their male counterparts in the Professional and Doctorate educational attainment levels during the decade, with males in the High School, Some College, and Bachelor's levels showing the largest decrease in salary. 


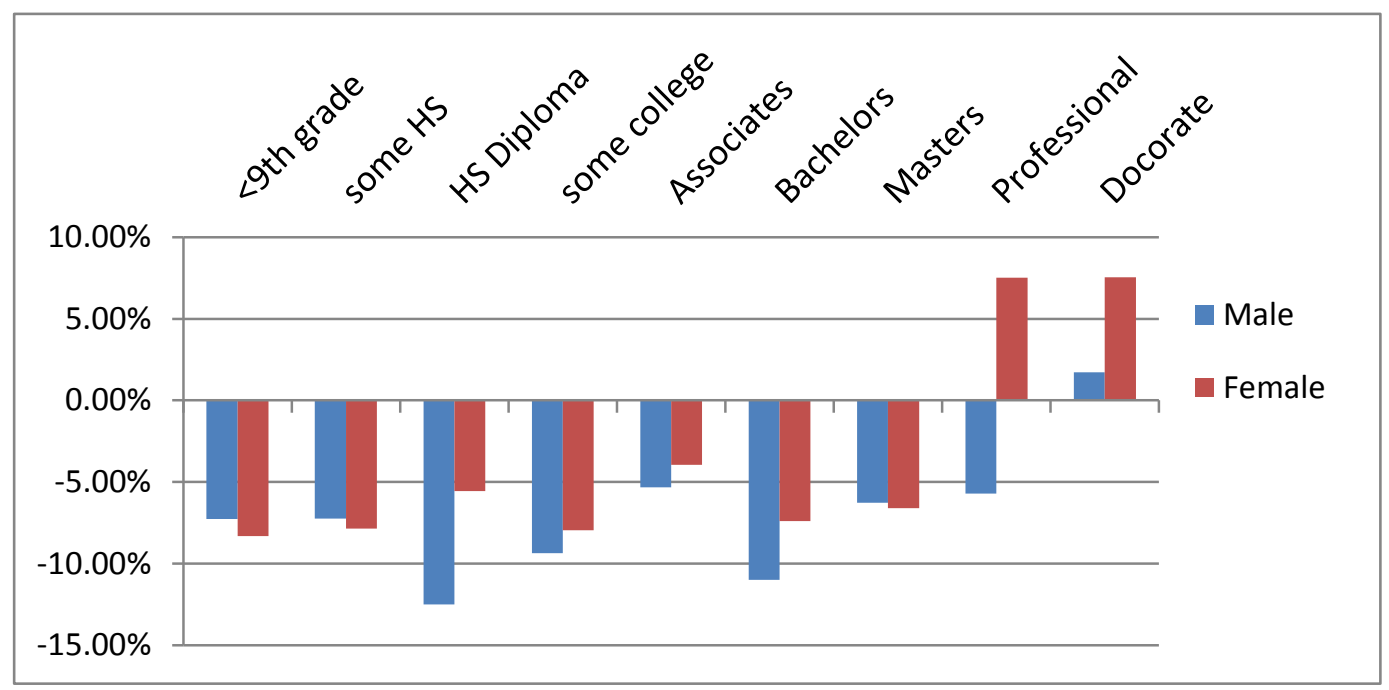

Figure 3. 2001-2010 Real Salary Changes

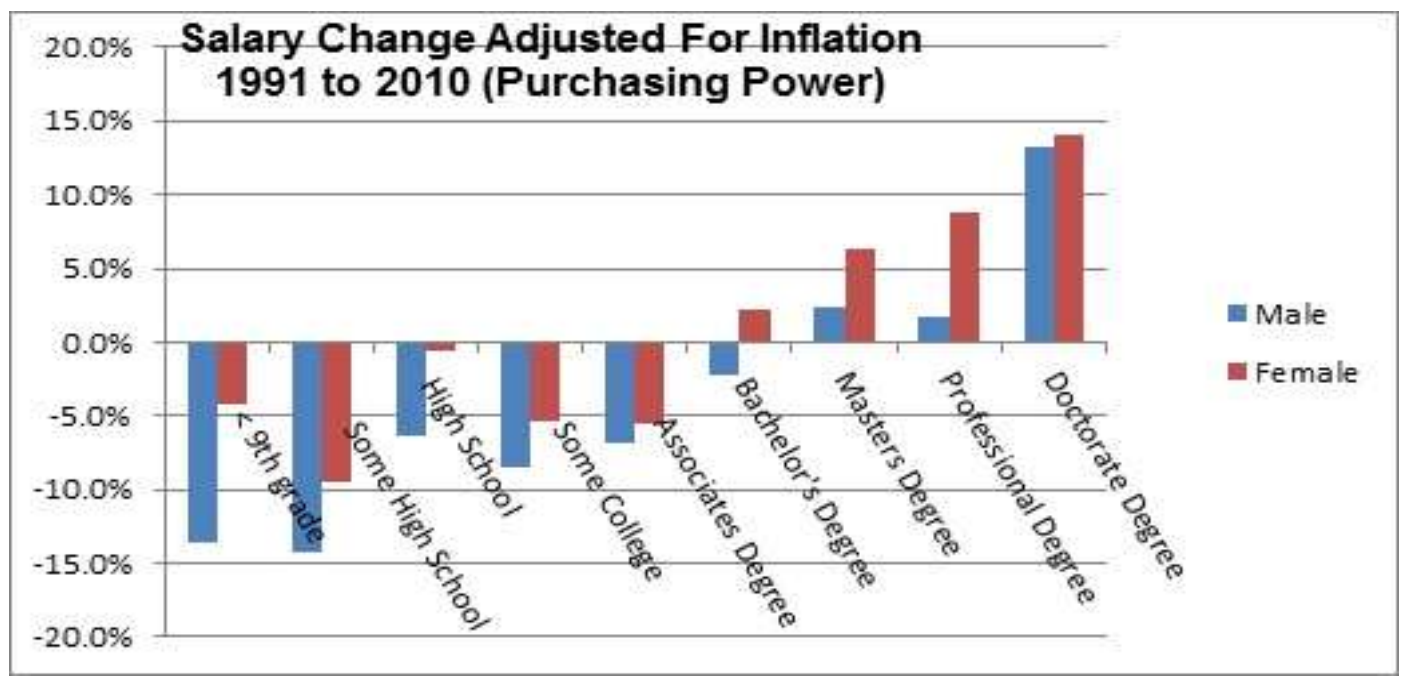

Figure 4. 1991-2010 Real Salary Changes

Figure 4 combines the data from three business cycles over a 20 year period that encompasses 1991 through 2010, measuring buying power, which is the salary adjusted for inflation. Several trends are evident:

- Females generally fared better than their male counterparts, in terms of salary change; however, females have a lower salary, in terms of dollars per year

-The buying power of males below a Master's Degree and females below a Bachelor's Degree, declined from 1991 through 2010

- The wealth gap between the educated and the highly educated is widening

- The standard of living is declining for most people in the U.S., which encompasses all degree levels below a Bachelor's Degree.

-While females showed a small increase at the Bachelor's Degree level, males showed a nearly identical decrease. A Bachelor's Degree, therefore, merely maintained pace with inflation.

-A Master's Degree or higher is necessary to improve the standard of living. This is important because this currently excludes $86 \%$ of the workforce. 


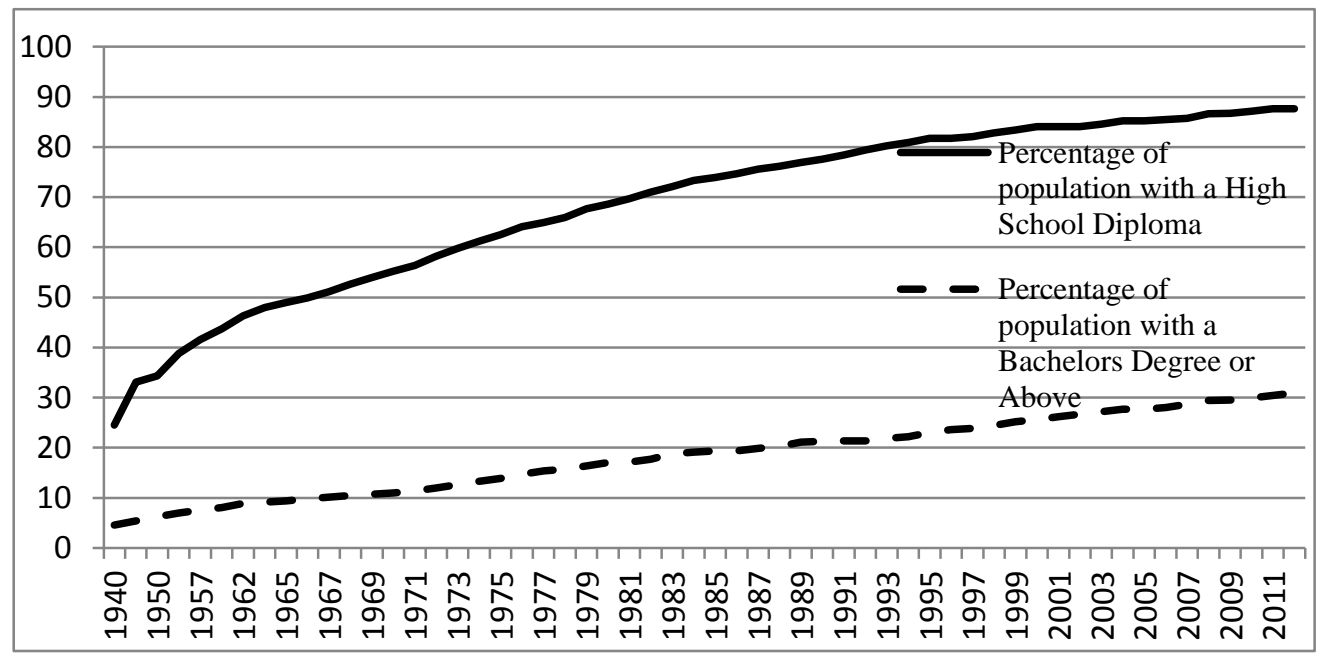

Figure 5. Percentage of the population who have completed high school or college: age 25 years and older from 1940-2012. Source: U.S. Census Bureau, CPS and decennial censuses, author formatting

\section{Discussion and Projections}

Based on the two decade study of salaries, the data has illustrated that the wealth gap is increasing and the standard of living is decreasing for all educational levels below a Bachelor's Degree. As a result, these trends could have a major impact on the economy of the United States over the long haul. Using the data trends from 1991 through 2010, salary projections were calculated through the year 2030. The projections were calculated with the underlying assumptions that the trends in years 2011 through 2030 would mirror the trends that occurred 1991 through 2010, in terms of economic conditions, educational attainment, and salaries.

Table 3. Projection to 2030

\begin{tabular}{|c|c|c|c|c|c|c|c|c|c|}
\hline MALES & $<9$ th Grade & some HS & $\begin{array}{l}\text { HS } \\
\text { Diploma }\end{array}$ & $\begin{array}{l}\text { some } \\
\text { college }\end{array}$ & Associates & Bachelors & Masters & Professional & Doctorate \\
\hline 2010 & 24450 & 29440 & 40060 & 46430 & 50280 & 63740 & 80960 & 115300 & 101220 \\
\hline 2030 & 21328 & 25505 & 37603 & 42672 & 46971 & 62338 & 82893 & 117201 & 115435 \\
\hline \multicolumn{10}{|c|}{ FEMALES } \\
\hline 2010 & 18,240 & 20,880 & 29,860 & 33,400 & 37,770 & 47,440 & 59,100 & 76,740 & 77,390 \\
\hline 2030 & 17501 & 18994 & 29666 & 31661 & 35743 & 48504 & 62954 & 83724 & 89020 \\
\hline
\end{tabular}

As seen in Table 3, the male and female projections showed profound results in real salary changes based on 1991-2010.

Table 4. Female pay

\begin{tabular}{llllllllll}
\hline \multicolumn{10}{c}{ Female pay as a percentage of male pay } \\
\hline 1991 & $70 \%$ & $68 \%$ & $68 \%$ & $70 \%$ & $70 \%$ & $74 \%$ & $69 \%$ & $71 \%$ & $70 \%$ \\
2010 & $75 \%$ & $71 \%$ & $75 \%$ & $72 \%$ & $75 \%$ & $74 \%$ & $73 \%$ & $67 \%$ & $76 \%$ \\
2030 & $82 \%$ & $74 \%$ & $79 \%$ & $74 \%$ & $76 \%$ & $78 \%$ & $76 \%$ & $71 \%$ & $77 \%$ \\
\hline
\end{tabular}

Table 4 illustrates female pay as a percentage of male pay 1991, 2010, and 2030.

Males lost buying power in all degree attainment levels below a Master's degree. Females lost buying power in all degree attainment levels below a Bachelor's Degree. While females closed the salary gap between their male counterparts in nearly all attainment levels, the gap decreased minimally, by percentage. By 2030 , females with a Doctorate Degree were projected to be making $77 \%$ of the salary earned by their male counterparts, compared to $76 \%$ in 2010 . This is an increase of just $1 \%$ over the 20 year period, which is not statistically significant. Females made 
larger strides toward equalizing pay among the sexes in the lower attainment levels. For example, in the $9^{\text {th }}$ grade attainment level, females showed an increase of $7 \%$ in the ratio of the salary earned by their male counterparts over the 20 year period. While this is a positive trend that will, ultimately, reach a level of comparative pay for females, it will take hundreds of years to equalize, under the study conditions.

Table 5. Doctorate level ratio

\begin{tabular}{ccc}
\hline Male & 1991 & 3.25 \\
\hline & 2010 & 4.14 \\
Projected & 2030 & 5.41 \\
\hline
\end{tabular}

Table 5 shows the ratio of Doctorate level $<$ than 9 th grade level.

Wealth gap analysis projections were also profound. When comparing the ratio of $9^{\text {th }}$ grade attainment to Doctoral attainment, a large increase was illustrated. The wealth gap in 2010 was 4.14, while it was projected to increase to 5.41 by 2030 , which is a significant increase in the educational attainment wealth gap.

\subsection{Future Research}

Recommendations for future research include the following:

-Supply and demand changes in the workforce, as related to educational attainment.

-The impact of the increase in the percentage of degree holders on salaries.

-The impact of underemployment on wage growth and salary, as related to educational attainment.

-Labor mobility and the relation to structural unemployment.

\section{Conclusion}

The research validated that that there is documented value in higher education, supporting all of the study hypotheses. In addition, it illustrated that the wealth gap, related to educational attainment, is growing wider.

Females, generally, did better than their male counterparts, in terms of salary change: however, females have a lower salary in terms of dollars per year.

- The purchasing power of males below a Master's Degree and females below a Bachelor's Degree declined from 1991 through 2010.

-The standard of living is declining for $70 \%$ people in the United States.

-The gap between the rich and the poor is widening.

- Annual average Female salary growth has outpaced male salary growth $.47 \%$ for $<9^{\text {th }}$ grade level to $.04 \%$ for Doctorate over the 1991 to 2010 time period.

As education level increases (Master, Professional, and Doctorate Degrees), the salary increases respectively and the wealth gap widens. The Bachelor's Degree attainment level keeps pace with inflation, but does not show an increase in the standard of living. Thus, a Bachelor's Degree is the minimum degree attainment level needed to maintain standard of living and not lose buying power. As education level increases, salaries are less volatile to changes in economic conditions. This research supports the study orchestrated by Dr. Hicks in the Labor Law Journal (2013), indicating that the wage gap between Americans with higher education degrees and high school or below education has continued to widen, even in the face of several economic recessions, including the most recent recession.

The wage gap between workers at different levels of educational attainment has continued to widen, favoring more educational attainment. Compensation is positively correlated with educational attainment.

\section{References}

Bureau of Labor Statistics. (2009). Labor force statistics from the current population survey. Retrieved from http://www.bls.gov/cps/cps_htgm.htm

Bureau of Labor Statistics. (2012). Education pays. Retrieved from http://www.bls.gov/emp/ep_chart_001.htm/

Campbell, H., \& Morgenson, G. (2002). Dictionary of Money and Investing. Retrieved from http://www.duke.edu/ charvey/

Farlex Financial Dictionary (2012). Economic downturn. Retrieved from http://financial-dictionary.thefreedictionary.com/Economic+downturn 
Hendricks, L.A. (2007). How important is discount rate heterogeneity for wealth inequality? Journal of Economic Dynamics and Control, 31(9), 3042-3068. http://dx.doi.org/10.1016/j.jedc.2006.10.002

Hendricks, L.A. (2007). The intergenerational persistence of lifetime earnings. Retrieved from http://www.lhendricks.org/Research/Rev2_IGM_Paper.pdf

Hicks, M. J. (2013). Labor markets after the great recession: Unemployment and policy for Indiana. Labor Law Journal, 64(2), 103-113.

International Monetary Fund. (2009). What is a recession? Retrieved from http://www.imf.org/external/pubs/ft/fandd/2009/03/basics.htm

InvestorWords. (2013). What is a recession? Retrieved from http://www.investorwords.com/4086/recession.html

Michael, N. (2013). Education and Unemployment. Retrieved from http://www.financialramblings.com/archives/education-and-unemployment/

Mincer, J. (1991). Education and unemployment. The National Bureau of Economic Research. Retrieved from http://www.nber.org/papers/w3838

Moriguchi, C., \& Saez, E. (2008). The evolution of income concentration in Japan 1886-2005: Evidence from income tax statistics" with Chiaki Moriguchi. The Review of Economics and Statistics, 90(4), 713-734. http://dx.doi.org/10.1162/rest.90.4.713

National Center for Education Statistics. (2012). Digest of education statistics, 2011. Retrieved from http://nces.ed.gov/programs/digest/d11/ch_3.asp

Ryan, C., \& Siebens, J. (February 2012). Educational Attainment in the United States: 2009. U.S. Census Bureau. Retrieved 25 February 2013.

Saez, E. (2004). Reported incomes and marginal tax rates, 1960-2000: Evidence and policy implications. In J. Poterba (Ed.), Tax Policy and the Economy, 18 (pp. 117-172). Boston: The MIT Press. http://dx.doi.org/10.3386/w10273

United States Census Bureau. (2010). American community survey. Retrieved from http://factfinder2.census.gov

\section{(c) $)$ EY}

This work is licensed under a Creative Commons Attribution 3.0 License. 